\title{
NAVIGATING THE CUMULATIVE EFFECTS OF FAMILY LANGUAGE POLICY DURING CHILDHOOD FOR IMMIGRANT YOUTH IN CANADA
}

\author{
KATHERINE MACCORMAC ${ }^{1} \&$ MEGAN MACCORMAC ${ }^{2}$ \\ ${ }^{1}$ University of Western Ontario, Faculty of Education, 1151 Richmond Street, London, Ontario, Canada. \\ ORCID: 0000-0003-2377-6998, Email: kmaccorm@uwo.ca \\ ${ }^{2}$ University of Western Ontario, Department of Sociology, 1151 Richmond Street, London, Ontario, \\ Canada. ORCID: 0000-0003-0703-1291, Email: mmaccor2@uwo.ca
}

\begin{abstract}
One of the most influential decisions that immigrant parents must make for their children involves establishing a set of rules and norms governing what language(s) they will be raised with and how they will acquire proficiency in the dominant languages of the host society, a process known as family language policy. Such decisions can have long lasting effects for immigrant children into adulthood by influencing their integration into the host society and transition towards adult life. Using retrospective, in-depth interview data collected from young immigrant adults, this study explores the ways that parental decisions made throughout an immigrant child's life course regarding language use and learning shape their multilingual identity and attitude towards the use of multiple languages in their everyday adult life. Findings suggest that the linguistic decisions parents make in the early years of an immigrant youths' life have lasting impacts on them in terms of connecting to family members and culture in adulthood. We found that when parents created either a flexible or strict family language policy, such policies produced more positive experiences in the migration and early settlement process for immigrant youth compared to those whose parents did not form a family language policy. KEYWORDS: Family language policy, Migration, Language shift, Parent-child relations, Childhood inequality, Language maintenance
\end{abstract}




\section{INTRODUCTION}

Immigration, family language policy, and social factors impacting language maintenance goals

$\Lambda$ s s immigrant children and their families adjust to post-migration life, they must make quick decisions regarding their children's future in order to propel them towards upward social mobility. Such decisions can have long lasting effects for immigrant children into adulthood by influencing their integration into the host society and transition towards adult life. Operating at the family-level, one of the most influential decisions that immigrant parents must make involves establishing a set of rules and norms governing what language(s) their children will be raised with and how they will acquire proficiency in the dominant languages of the host society, a process known as family language policy (Canagarajah 2008; Curdt-Christiansen 2009; Schwartz 2010; King and Fogle 2013). The assimilative pressures associated with the immigration process are one of the main reasons why immigrant families opt to create a family language policy (Fishman 1965).

Underlying the development of family language policies are parental beliefs about language which are formed through interactions with different social structures, institutions (i.e. social, political, and economic), dominant language ideologies (Canagarajah 2008; Curdt-Christiansen 2009; King \& Fogle 2013) as well as the parents' past childhood experiences being raised in a completely different social context than that of their immigrant children (Bodvarsson \& Van den Berg 2010). Also influencing parental decisions about language use and maintenance goals are agentic power dynamics between immigrant parents and their children. Here, such dynamics can cause families to either change or modify language policies to meet the needs of the family unit. In this case, family language policies are viewed by family members as fluid rules that can shift overtime as parents and children adapt to wide-ranging societal and linguistic norms encountered in their everyday lives (Gafaranga 2010; Schwartz 2010). From a cultural development standpoint, the early decisions that parents make regarding the development of family language policies largely determine if heritage languages are transmitted from generation to generation or whether a shift in language(s) will take place (Fishman 1991).

Despite their best efforts, the demands of the migration process do not always represent an easy path forward for immigrant parents when it comes to developing policies for the use and maintenance of languages within the family unit (Bacallao \& Smokowski 2007; Kim, Conway-Turner, Sherif-Trask, \& Woolfolk 2006). In some cases, the planning and development of family language policies within immigrant families hinges on whether the increased demands of economic and social survival in the host society will take greater priority over language maintenance goals. When economic survival becomes part of the family language planning process, immigrant parents often find themselves in the difficult position of shifting their parenting strategies to adapt to their new lives and social roles in the host society (Bacallao \& Smokowski 2007; Kim, Conway-Turner, Sherif-Trask, \& Woolfolk 2006).

Studies have shown that shifts in parenting can have a direct and cumulative impact 
on the relationship and attachment that immigrant children form with their mother tongue(s) (Fishman 2001). For example, as less parental guidance and time is devoted to maintaining linguistic customs from the country of origin, immigrant families are more likely to experience a linguistic shift to the majority language of the host society. As such, the parental role in transmitting linguistic skill sets to children is positively associated with the transmission of inequality across generations as diverse multilingual repertoires become replaced by a shift towards monolingualism (Stevens \& Ishizawa 2007; Nesteruk 2010). Parental decisions to reduce the use of heritage language(s) post-migration is often strongly related to the needs of social acceptance of the family in the new society and economic survival of being disadvantaged prior to migration (Canagarajah 2008).

\section{Language shift shaped through linked lives and generational forces}

Although the terms "immigrant" and "migrant" are often thought of as statuses describing an individual, research on the immigration process shows that it is an important life course event linking individuals over multiple generations (see Glick 2010; Jasso 2003; Elder 1994). For instance, when young children migrate with their parents, the distinctive parental roles that mothers and fathers perform during the migration process greatly impacts the child during the migration and resettlement process. Both Elder (1994) and Hagan, MacMillan, and Wheaton, (1996) identify that strong parental support during and after the migration process is positively associated with successful adaptation to the new host society for immigrant children. Conversely, when fathers exhibit indifferent or unsupportive parenting styles during and after the migration process, children are far more likely to have difficulty coping in their new surroundings (Hagan, MacMillan, \& Wheaton 1996).

Evidence overwhelmingly suggests that mothers play an integral role in fulfilling the family's language maintenance goals by not only reinforcing language use through family interactions, but also by supporting the linguistic development of their children both inside and outside the home (Nesteruk 2010; Tannenbaum 2003). The primary motivation behind this role is often fueled by maternal beliefs that the maintenance of the family's mother tongue(s) will aid in intergenerational communication with extended kin and provide their children with an added linguistic skill for increased academic and economic success. For many immigrant mothers, they see their role in the process of family language policy and planning as being that of a gatekeeper who provides a bridge for the family between their pre- and post-migration linguistic selves (Kwon 2017).

Childhood inequality and cumulative processes of dis/advantage strongly influence an individual's life-trajectory and later life socioeconomic position (Calasanti \& Slevin 2001). Theories of cumulative inequality explain that "childhood conditions are important for explaining adult functioning and well-being" (Ferraro \& Shippee 2009: 335 ) and that the decisions made by parents for their children in these early developmental years accumulate over the life course and can impact the child into adulthood (Dannefer 2003; Elder, Johnson, \& Crosnoe 2003; Garbarski 2014). As argued by 
Willson, Shuey and Elder (2007), individuals with high levels of cumulative inequality can compensate for "early disadvantage [which] can shift individuals onto different trajectories, as studies of resilience in the face of disadvantage have shown" (p. 1913). The pathway to doing so, however, is often challenging and difficult.

In terms of family language policy and planning in childhood, decisions made regarding the process of learning languages can impact the quality of life the family has in the new host society. For example, Hurtado and Vega (2004) find that when immigrant children migrate to a society with a different language than that of their mother tongue, higher levels of competence in the new host society language is associated with increased social acceptance by their school peers. Additionally, evidence suggests that families with low linguistic competence of the dominant language of the host society face several issues regarding access to proper medical services, health insurance, and doctor visits which can impact the health and development of children during the critical early developmental stages (Yu, Huang, \& Schwalberg 2006). Canagurajah (2008) finds that for "previously disadvantaged groups, the new life in the West and the possibilities of acquiring English freely in both everyday life and in formal settings [serve] as a source of empowerment” (p. 159). Consequently, these studies demonstrate that the lived experiences of immigrant families prior to immigration has a strong influence over the structure of the family language policy post-migration.

\section{Role of education in transforming language policies and priorities}

Not only do economic factors both pre- and post- migration influence the way that immigrant families make decisions about the structure of their family language policies, but the contact that immigrant children make with languages at school can have a direct impact on transforming and shifting the priorities of such policies. For example, as young immigrant children become immersed in new social environments through education, they are more likely to acquire the dominant language(s) and cultural norms of the host society much quicker than their parents (Canagarajah 2008). Research shows that increased contact between immigrant children and the dominant language(s) of the host society (i.e. schooling and new peer groups) often results in children choosing to distance themselves from or reject established family language policies and practices (Kwon 2017). In some cases, immigrant children experience a significant amount of pressure through schooling and peer relationships to assimilate to the linguistic and cultural norms of their classrooms. Here, knowledge of the dominant language(s) of the host society increases the child's chance of social survival as they form new social relationships (i.e. student-teacher; peer groups) and encounter contrasting ideas about language (Zhang \& Slaughter-Defoe 2009).

Over time, it is very common for immigrant children to develop the belief that knowledge of a minority language is of little value for their future success in the host society. Interestingly, this belief runs counter to established research findings

(see Brown 2009; Lee 2002; Shin 2005; You 2005) which indicate that maintaining an immigrant child's mother tongue is crucial for promoting "academic achievement, ethnic identity, and integration into wider society” (Kwon 2017: 496). Often against 
their parents' best efforts at supporting language maintenance goals, these children are more likely to self-initiate the process of language shift as an adaptation strategy (Kang 2010; You 2005), a practice which is particularly prevalent among immigrant students from minority language backgrounds and those who experience different forms of linguistic discrimination at school (Park 2017; Tse 2001). As such, school experiences contribute to generational differences between the linguistic abilities and cultural sensibilities of parents and children (Tuominen 1999).

In a study of immigrant children living in multilingual households, Luykx (2005) finds that children possess a strong sense of agency in the family unit by assisting parents in the socialization process. Here, children serve as language brokers and communication facilitators imparting their school-based knowledge of basic vocabulary and societal norms to their parents. Corsaro (2018), as cited in Odrowąż-Coates (2019), finds that being in such a position can bolster a migrant child's confidence in their linguistic abilities by shifting the balance of power from their parents to themselves as the primary communication facilitator. In fact, although parents often create family language policies aimed at the transmission and usage of certain languages for their children, such policies are heavily influenced by the children themselves through their increased daily contact with the language and culture of the host society (Luykx 2005).

It is important to note, however, that despite their influence in the language policy making process at the family-level, there are relatively few studies which are solely dedicated to exploring the role that immigrant children play in forming, maintaining, and changing family language policies. The gap in knowledge comes despite it being known among language and migration researchers that children do in fact play an active role in developing, shifting, and maintaining family language policies through their interactions both inside and outside the home (Canagarajah 2008; Fishman 2001; Luykx 2005; Corsaro 2018 as cited in Odrowąż-Coates 2019). In fact, research demonstrates that when immigrant parents acknowledge and support their children's active participation in the family language policy making process (i.e. desires for acquisition, maintenance and use of multiple languages during their childhood), these youth are less likely to drop out of school than children raised in monolingual families and have lower levels of emotional and behavioural problems (Feliciano 2001; Han \& Huang 2010).

Creating family language policies among Canadian immigrant families within the context of officially bilingual Canada

In recent years, Canada has transformed itself into a vibrant multilingual and multicultural mosaic through increased transnational migration. Today, 2.2 million Canadian children, totaling $37.5 \%$ of the population, come from an immigrant background with over half tracing their heritage back to Asia. Based on current immigration rates, by the year 2036, this number will rise to $39 \%-49 \%$ of the population (Statistics Canada 2017).

Recent migration research in Canada reveals that despite increases in linguistic diversity within Canadian society, Canadian immigrant youth from minority lan- 
guage backgrounds often face widespread discrimination when it comes to the use of non-official language knowledge in Canadian schools. As they shift between home and school worlds, these youth often encounter conflicting sets of beliefs about language between the policies established at home by their parents and the dominant norms and expectations concerning acceptable language use and learning established in Canadian schools. As a result, many find themselves in the difficult decision of having to leave their rich linguistic knowledge at the classroom door to compensate for the linguistically segregated nature of their education where little value is placed on knowledge of multiple languages. The conflicting nature of their language experiences post-migration can have long lasting negative effects on how these youth see themselves as multilingual Canadians and their attitudes towards the use of multiple languages in the transition to adulthood (Mady 2012; Cummins 2014).

Despite the linguistically segregated nature of Canadian classrooms, research has shown that when parents promote the utilization of multiple linguistic competencies among their children, it can have several positive outcomes for immigrant children in later life especially when navigating linguistic norms between home and school worlds. For instance, when immigrant parents support their children's language acquisition, maintenance, and use of multiple languages during their childhood, these children are less likely to drop out of school than children raised in monolingual families and have lower levels of emotional and behavioural problems. As such, family language policies which focus on cultivating both mother tongue languages and the dominant languages in the host society, positively assist immigrant youth with their transition from childhood to adulthood (Feliciano 2001; Han \& Huang 2010).

\section{OBJECTIVES AND PURPOSE OF THE STUDY}

Although research has been conducted on the cumulative effects of family language policies and planning on the linguistic and identity development of immigrant youth, studies examining early childhood experiences of immigrant youth are limited in their scope by focusing largely on immigrant youth from the same ethnic group, country or socioeconomic background. As a result, a significant gap exists in our knowledge of the sociocultural environments that immigrant youth grow up in and the role that families and parents play in shaping the migration process and experiences of their children (Glick, Walker, \& Luz 2013). Similarly, there are few studies that show the role that children play in forming, negotiating, or modifying the family language policy despite strong evidence that children play an important role in this process.

Accounting for the role that families and parents play in the migration process, our study contributes to the conversation by examining the cumulative impacts of parental decisions regarding language use and learning on the development of Canadian immigrant children's linguistic identities and attitudes towards the use of multiple languages throughout their life courses. Additionally, our study pushes the conversation forward by accounting for the role that children play in the family language policy making process. To explore this issue, we framed our investigation around the following research question: In what ways do parental decisions made throughout an 
immigrant child's life course regarding language use and learning shape their multilingual identity and attitude towards the use of multiple languages in their everyday adult life?

\section{STUDY DESIGN}

\section{Examining the migration process from the life course perspective}

The life course perspective was used to frame the analysis of this study. According to Elder, Johnson, and Crosnoe (2003), the perspective "guides research on human lives within context" (p. 10) by accounting for change in life course patterns while considering historical time and sociocultural context (Mayer 2009). The guiding principles of the life course perspective, as outlined by Elder (1994), are strongly embedded in the study of migration and assist data analysis by focusing on how transitions, relationships, and socio-historical processes shape an individual's life trajectory (Hutchinson 2007). There are five principles that give rise to the life course perspective which are: 1) the principle of life span, 2) the principle of agency, 3) the principle of time and space, 4) the principle of timing, and 5) the principle of linked lives.

Of utmost importance to the framing of our investigation are the principles of time and space and linked lives. By applying the principle of time and space to our study, it aids our understanding of the familial context shaping the migration process and provides important contextual background regarding the conditions that immigrant youth grew up in pre-migration and were raised with post-migration. Framing our analysis with a focus on context also helps to identify differences in the experiences for immigrant children who are being raised in different historical and cultural environments compared to that of their parents. The life course principle of linked lives provides context for understanding how developmental and life trajectories are shaped bidirectionally by both parents and children. An important aspect of studying linked lives is through the examination of the social convoys which highlight the "historical, cultural, and structural risks, resources, and constraints shaping life chances and life quality. Social convoys are a key part of the contexts in which individuals' beliefs, behaviors, and strategic adaptations play out” (Moen \& Hernadez 2009: 266). For immigrant youth, their lives are typically shaped through contact with parental and extended family bonds that can be either geographically close or distant to the individual. Accordingly, by exploring the principle of linked lives through the role that parents play in shaping the linguistic repertoires of immigrant youth, this study provides a more comprehensive understanding of how the migration process impacts the life trajectories of immigrant youth overtime.

\section{Participants}

Our study involved the analysis of in-depth interview data from 13 participants. Prior to recruiting participants to take part in the study, ethical approval was obtained through the Non-Medical Research Ethics Board at a research-intensive university in South Western Ontario, Canada. Participants were recruited using a combination 
of mass-recruitment student emails, recruitment posters placed in high traffic areas within university departments and libraries, email recruitment through student cultural clubs on campus, and email and poster recruitment through university departments and faculties. To participate in the study, participants had to be: 1) 18 years of age or older; 2) born abroad and immigrated to Canada as a child, adolescent or young teen; 3) previously enrolled in a French second language program for a minimum of three years (i.e. Core French; French Immersion, etc.); and 4) currently have knowledge of one of more of Canada's two official languages (English and French) and one or more non-official languages. In total, 13 participants were recruited and gave their written informed consent to take part in the research all of which identified as female.

Table 1. Interview participant demographics

\begin{tabular}{ccc}
\hline \multicolumn{2}{c}{ Participant demographics } & \\
\hline Age at immigration to Canada & $\mathrm{N}$ & \\
$0-4$ & 4 & 30.80 \\
$5-7$ & 6 & 46.15 \\
$8-9$ & 1 & 7.70 \\
$10+$ & 2 & 15.38 \\
& & \\
Immigrant status on entry to Canada & & 76.92 \\
Economic immigrant & 10 & 23.07 \\
Refugee & 3 & \\
& & 38.46 \\
Country of origin & & 7.70 \\
China & 5 & 7.70 \\
Taiwan & 1 & 23.07 \\
Pakistan & 1 & 15.38 \\
Colombia & 3 & 7.70 \\
Korea & 2 &
\end{tabular}

Number of languages known before migration

$\begin{array}{lll}1 & 4 & 30.74 \\ 2 & 6 & 46.15 \\ 3+ & 3 & 23.07\end{array}$

Language plan pre migration

$\begin{array}{lll}\text { Yes } & 8 & 61.50\end{array}$

No $\quad 5 \quad 38.50$

Maintained mother tongue in Canada

$\begin{array}{lrr}\text { Yes } & 10 & 76.90\end{array}$

No $\quad 3 \quad 23.10$

Family language policy

$\begin{array}{lll}\text { Flexible policy } & 6 & 46.20\end{array}$

Strict adherence policy $\quad 4 \quad 30.80$

No established policy $\quad 3 \quad 23.10$

Table 1 shows demographic characteristics for the participants who took part in our research study. The 13 participants ranged in age from 18-30 years old and immi- 
grated to Canada between the years of 1998-2010. At the time of their immigration to Canada, the participants ranged in age from 2-12 years old. Their countries of origin included China, Taiwan, Pakistan, Colombia, Korea, and Singapore. Three of the participants immigrated to Canada with their families as refugees and ten immigrated within their parents for economic/work related opportunities. Upon arrival to Canada, many of the participants settled with their families in the province of Ontario with only two participants settling in the provinces of Québec and British Columbia respectively before making Ontario their permanent home. Among all of the participants, three were multilingual before immigrating to Canada (i.e. knowledge of three or more languages), six were bilingual (i.e. knowledge of two languages) at the time of their immigration and became multilingual while growing up in Canada, and four were raised monolingual (i.e. knowledge of one language) but became multilingual while growing up in Canada.

\section{Methods of data collection}

Data were collected in two phases beginning with an initial in-depth interview followed by a subsequent follow-up in-depth interview. The approach taken to conduct both interviews followed the narrative interviewing method. As a data collection method, narrative interviews involve collecting stories about an individual's life experiences which are then used to understand the phenomenon under study (Ayres 2008; Kartch 2017). Due to their open-ended nature, narrative interviews are "the least structured type of interview and tak[e] a different type of pre-interview planning" (Kartch 2017: 1074). Here, the "researcher is not looking for answers to questions; rather, he or she is looking for the participant's story” (Kartch 2017: 1074). Narrative interviewing “[r] epresents a shift in the way roles are conceptualized: from interviewer-interviewee into narrator-listener" (Kartch 2017: 1074). Throughout the interview, the researcher acts in the role of "facilitator" (Kartch 2017: 1074) whose job is to provide a space for participants to explore the underlying meanings which define their personal narratives (Kartch 2017).

Since the interview was conducted using the narrative interviewing method, as the participants were sharing their story, improvised follow-up questions were asked for clarification purposes or to extend conversations on topics of interest which arose throughout the course of the interview. Each initial interview lasted between an hour and an hour and a half in length and was audio-recorded. It was important to the researchers to take a participant-centered approach when collecting the data by including a follow-up interview. The follow-up interview not only served as a way to incorporate another layer of participant voice into the interpretation process, but it was also important for reducing the potential for researcher bias by grounding the analysis/interpretation in the participants' voices, knowledge(s), and life experiences. As was the case with the initial narrative interview, each follow-up narrative interview lasted between an hour and an hour and a half in length and was audio-recorded. 


\section{Methods of data analysis}

Data analysis took part in four phases and all data were organized and analyzed using the mixed-methods data analysis software MAXQDA. Phase one of the analysis involved using MAXQDA's coding tools to complete a lexical search of both the initial and follow-up interview transcripts for each participant. The lexical search included words related to family members such as: family, mom or mother, dad or father, parent or parents, brother, sister, sibling(s), cousin(s), aunt(s), uncle(s), grandma, grandpa, or grandparents. Once the data were coded using the lexical search function, the memo function was then used to record analytical summaries about the memories which the participants attached to certain family members. The process involved creating a series of memo notes while reviewing the moments in each participant's set of interview transcripts when they mentioned a family member or a particular family interaction of significance to the investigation.

Once all the notes were recorded in MAXQDA for each participant's set of transcripts, they were then compiled together in a separate document in MAXQDA and used to create a series of family case summaries. According to Knafl and Ayres (1996), family case summaries "enable the investigators to reduce a large qualitative data set in a way that preserves the family focus of the research" (p. 350). In the case of our investigation, utilizing this technique provided the contextual background necessary to develop the thematic codes for further in depth analysis that maintained both the viewpoint of the interviewee while accounting for the familial context of their migration journey and integration into Canadian society.

The family case summaries were created individually for each participant based on the analytical notes for their interview responses and later cross-compared to look for similarities and differences in how each participant talked about their family in relation to their language and adaptation experiences. The notes used to create the family case summaries were organized under the following subheadings in order to create a family narrative from the perspective of the interviewee: 1 ) pre-migration experiences, 2) family efforts to prepare for migration, 3) early experiences in Canada, 4) cultural continuity learning mother tongue, 5) school experiences, 6) role as a translator for parents in Canada, 7) mother's influence, 8) father's influence, and 9) extended family influences.

After the case summaries had been created for each participant, they were then coded to examine how each interviewee felt during the moments where they mentioned different family members. These memories were coded with a simple experience scale of positive, indifferent, and negative to rate the emotions attached to the different life experiences each participant chose to reflect on during their individual interviews. Coded segments which were rated positive often mentioned feelings of being supported, happy, or proud. By contrast, those coded segments which were rated negative, included feelings of sadness, loneliness, and confusion. Lastly, coded segments rated as indifferent referred to memories that were shared which did not have a clear indication of how the participant felt at the time or what emotions they attached to a childhood experience. 


\section{FINDINGS AND RESULTS}

\section{Importance of Incorporating a Family Language Policy into the Migration Process}

The analysis of the data produced several results which were both consistent with the literature and pushed the conversation forward in new directions. Of noteworthy mention is differences which were observed between the experiences of those immigrant youth whose families had a flexible or strict family language policy pre- and post-migration and those who had no established family language policy. As seen in Table 2, when comparing the experiences of those participants who did not have an established family language policy and those who had a flexible or strict family language policy prior to migration, a significant difference was noted in reporting negative memories pre- and early post- migration to Canada (31.6\% and $14.3 \%$ respectively). When analyzing our data, we discovered that $66 \%$ of the coded family case studies associated negative emotions with their migration experience when no established family language policy was present during and after migration. Similarly, if participants did not have a family language policy guiding the migration process both pre- and post- migration, they were also more likely than their peers to mention lasting negative cumulative effects impacting their transition to adulthood (i.e. difficulty relating to their immediate family members and to their heritage.

To illustrate the negative cumulative effects of having no established family language policy, one can look at the narrative of Eliza, a participant in our study who immigrated to Canada from her native China when she was seven years old. Throughout both of her narrative interviews, Eliza felt that her transition to Canadian society was rendered more difficult because there was no strategy put in place for learning either of Canada's two official languages prior to migration and no structured plan developed for maintaining her heritage language of Mandarin. Growing up as an immigrant youth in Canada, Eliza's parents did not force her to learn Chinese culture because they thought Western society was better from both a cultural and financial perspective. Eliza's story reflects the literature because when combined with the migration process, language often plays a complicated role in terms of relationships among immigrant families. Here, language has the ability to both "bin[d] and divid[e] family members" (Bammer 1994:100) because "not only do parents and children often end up with different native languages, their different relationships to these languages can have notable social consequences" (Bammer 1994:100). In Eliza's case, the parental decision not to provide language support to maintain her mother tongue had lasting cumulative effects by diminishing her ability to communicate in her native language and preventing her from fully connecting with her parents from a linguistic and cultural standpoint.

In addition to the frustration that Eliza experienced from not being able to connect with her native language and culture, she also believes that the lack of language support she received from her parents while adapting to life in Canada left her floundering to survive in a new linguistic and social environment. While reflecting on her migration experience, she described her mother's support for language learning as that of the 'sink or swim' model which left her feeling abandoned: 
I remember my mom buying a dictionary from the bookstore for me to kind of like be like oh yeah you've got a dictionary, you're good. It'll be fine. I was like ah no I don't want like...I was quite hesitant because I was like what I am going to do. I don't have any French background. There is no one in my family that speaks French. I just felt like I was going to suffer because I had zero supports at home. I spoke English, but like my parents barely even speak that so I just thought it was like a trap for me. Um, and then I went in and surely enough the first day I had no idea what was happening.

Table 2. Percentage of the case summaries coded in relation to the interviewee' pre and post migration experiences by family language policy

\begin{tabular}{lcccc}
\hline \multicolumn{5}{c}{ Percentage distribution } \\
\hline & \multicolumn{5}{c}{ FAMILY LANGUAGE POLICY } \\
\hline Experiences pre-migration & Flexible & Strict & None & Total \\
Positive & 10.5 & 14.3 & 0.0 & 7.9 \\
Negative & 10.5 & 0.0 & 25.0 & 13.2
\end{tabular}

Migration preparation

$\begin{array}{lcccc}\text { Positive } & 10.5 & 28.6 & 8.3 & 13.2 \\ \text { Negative } & 5.3 & 0.0 & 8.3 & 5.3\end{array}$

Early experiences in Canada

$\begin{array}{lcccc}\text { Positive } & 10.5 & 28.6 & 8.3 & 13.2 \\ \text { Negative } & 15.8 & 14.3 & 33.3 & 21.1\end{array}$

\section{School experiences}

\begin{tabular}{lcccc} 
Positive & 10.5 & 14.3 & 0.0 & 7.9 \\
Negative & 26.3 & 0.0 & 16.7 & 18.4 \\
\hline Total & $100 \%$ & $100 \%$ & $100 \%$ & $100 \%$ \\
\hline $\begin{array}{l}\text { (N) *number of coded family case } \\
\text { summaries }\end{array}$ & $\mathbf{6 ( 4 6 . 2 \% )}$ & $\mathbf{3 ( 2 3 . 1 \% )}$ & $\mathbf{4 ( 3 0 . 8 ) \%}$ & $\mathbf{1 3 ( 1 0 0 \% )}$ \\
\hline
\end{tabular}

For Eliza, and other participants in our study who did not have an established family language policy pre- and post-migration, they found the lack of linguistic support or strategies provided by their parents to be detrimental to their transition into the new society. Table 2 illustrates that for those who did not have an established family language policy, there were not any family case studies that were coded for positive experiences pre-migration. This finding is compared to $10.5 \%$ of coded family case summa- 
ries which were coded for positive experiences for those participants who had a strict or flexible language policy and successfully transitioned to life in Canada. When the participants discussed their early memories in Canada, those without an established family language policy were also nearly twice as likely than their contemporaries to report negative experiences in their early life growing up in Canada (33.3\%, 15.8\%, and $14.3 \%$ of the coded family case studies respectively).

In contrast to those participants who did not have an established family language policy guiding the migration process, those participants whose parents employed a strict or flexible family language policy pre- and post-migration were more likely to report having a smoother transition to life in Canada. The data from Table 2 show that the family case summaries for participants with a strict family language policy were five times more likely to be coded for positive experiences in their early experiences in Canada and school experiences compared to those family case summaries for participants with no established language policy (42.9\% and $8.3 \%$ respectively). Amy's case is illustrative of the contrast which was noted in the experiences of those immigrant youth who were raised with an established family language policy in place and those who had no established family language policy. While recounting her migration history, Amy, a participant in our study who immigrated when she was ten from her native Colombia explained that prior to immigrating to Canada at nine years old her grandmother took her to the local library where she took out books on Canada. As she explained, this experience was positive for her in terms of transitioning to the host society:

When I turned nine, umm we were in the...in the thinking of coming to Canada. When that occurred, I remember I was living with my grandma and I remember umm signing up for the library card and just taking out all the Canadian books. All of them. I was like they're all mine. I have to learn everything about Canada.

In her interview, Amy explained that in addition to the pre-migration linguistic support provided by her family, her mother's flexible approach to family language planning upon arrival to Canada helped her to maintain a strong sense of being a native Colombian while also learning what it means to be and become a Canadian. She described her home life as being a place where her knowledge of Spanish, English, and French were all valued and where she could truly be her authentic multilingual self:

The nice thing about at home was because my Mom did create a like a...a...judgement free zone-where like I could... at home I could just pretty much...if I wanted to build a fort, I'll build a fort.

The freedom to express herself in all capacities of her life was beneficial for Amy in terms of building strong bonds with her family members and helped her to foster a strong desire to experiment and learn different languages while transitioning to life in Canada. The sense of linguistic freedom and parental support for family language planning that Amy expressed in her interview shared many parallels with another participant in our study who grew up in Columbia and immigrated when she was two years old to Canada. For Lucia, the fact that her parents encouraged her to maintain 
her heritage language and gain proficiency in both of Canada's two official languages offered her a sense of pride of being a multilingual Canadian:

I guess that I could speak three languages was pretty cool...I know like when I would go to Colombia, like my [extended] family would be like wow! You can speak three languages.

For both Amy and Lucia, the strong linguistic support provided to them by their families both pre- and post-migration helped to foster a sense of pride in having a strong linguistic toolkit to draw on both as a child and in adulthood.

By comparing Amy and Lucia's stories to the other sets of coded family case summary data, we observed that the establishment of a family language policy plays a vital role in the successful transition of immigrant youth post-migration. As we learned from listening to our participants, when immigrant parents integrate a flexible or strict family language policy into the migration process, their children are better able to adapt to the increased linguistic demands of the migration process, to connect to their heritage language and culture, and are far less likely to experience lasting negative cumulative effects. Our results indicate that the creation and enactment of such policies aids in promoting a more positive migration experience for immigrant youth by providing them with the necessary linguistic and cultural support to successfully adapt to life in the host society. These results are consistent with established findings in the field of language and migration research which argue that when immigrant families implement a family language policy as part of their migration experience, their children have better educational and developmental outcomes than those immigrant children raised without a family language policy. Additionally, those immigrant youth who have a family language policy guiding their migration experience are also better able to maintain their heritage language into adulthood (King, Fogle, \& Logan-Terry 2008).

\section{Importance of Adapting Family Language Policies to the Evolving Needs of Immigrant} Youth

Surprisingly, and in stark contrast to those participants in our study who experienced positive support from their family's established language plans both pre- and post-migration, some participants whose parents created strict or flexible family language policies struggled in their transition to Canadian life. For example, although these participants had a strict or flexible family language policy guiding their migration experience, their parents did not seek input from the children themselves in the planning of the policy. As a result, the design of such policies failed to provide support for these youth to help bridge the gap between home and school worlds. One participant, Maya, who immigrated from Pakistan when she was seven years old, remembered her early days in Canada as those in which she wanted to only be a Canadian and remove herself from any association to Pakistani culture. She explained that she chose to adopt this policy as a coping mechanism to be better accepted by her peers. Since the language policy put in place by her parents did not incorporate any supports to help 
her with her with the daily challenge of striking a balance between the maintenance of her heritage language and culture and being accepted as 'Canadian', she felt that crafting her own personal policy helped her to adapt to the evolving situation of being an immigrant youth growing up in Canada:

I remember when like after...before it was just you know like when my family was watching that show I...I would not watch it, I wouldn't participate...I just felt like I remember at that time like some people would be like oh yeah I listen to like Punjabi music or this-and I...and I would like very proudly say oh I've never listened to it in my life- like you know it was a sense of pride to say oh I've never done that. Oh, I've never listened to that music like I've never watched that movie, I've never done this. So, it was always like a sense of...and I actually stopped doing those things even though I quite liked them. Like I refused to watch dramas, I refused to listen to music - I refused to do anything that was related to that part of me.

For Maya, it was very important for her to be seen by her peers at school as a Canadian in order to avoid being considered an outsider. Growing up, Maya's siblings all had peers who were South East Asian in their classes, however, for Maya, there was not a single student in her classes who shared a similar background to her. As a result, she chose to pull away from the cultural activities that were associated with her Pakistani heritage that her family was partaking in so that she would be seen among her peers as a true Canadian. In doing so, Maya resisted the family's language policy and refashioned it to better meet her immediate linguistic and cultural needs as an immigrant youth adapting to life in Canadian society.

Having listened to Maya's story and those of the other participants who expressed struggles with having a strict or flexible language policy, it is evident that incorporating the experiences of immigrant youth into the design of family language policies is just as important as having an established policy in the first place. Nevertheless, to be the most effective, such policies must be adaptable to the evolving linguistic and cultural challenges experienced by these youth as they move between home and school worlds. In doing so, such policies have the potential to act as an agentive tool for immigrant children by providing them with the linguistic and cultural support to successfully transition to the host society. Our findings are confirmed by the established literature which sees that through language learning, immigrant children are equally embedded in the process of creating a new sense of self (Canagarajah 2008; Espín 2006; Fishman 2001). As we found through analysis of our data, by acknowledging and incorporating the process of self-transformation within family language policy planning decisions, immigrant parents can better support the evolving needs of their children as they transition to life in the host society.

\section{Language Brokering and Feelings of Resentment Among Immigrant Youth}

In addition to discovering that having an adaptable family language policy aids in the migration process, we found that language brokering represents a significant source of 
frustration for many immigrant youths. For many of the participants in our study, the frustration came from the fact that these youth were children at the time of serving in the role of language translator, and just like their parents, were still learning the languages of the host society. Studies show that immigrant youth often find themselves in the role of language broker because they have more opportunities through schooling and peer groups to learn languages compared to adults (Ewart \& Straw 2001). By thrusting children into this role, "The power of children is increased because they become 'cultural brokers', whereas the power of parents is decreased because they depend on their children's assistance to survive in the new world" (Espín 2006: 248). Recent studies in the field of language and migration research have found that for some immigrant youth language brokering represents a source of agency and empowerment by placing greater value on the child's linguistic knowledge (Luykx 2005; Corsaro 2018; Odrowąż-Coates 2019). Nevertheless, as our results show, not all immigrant children view this role in a positive light. Some harbor feelings of resentment into adulthood from being forced into a role that they view is meant for adults.

Rose, a participant in our study who immigrated when she was three years old from China, provides an illustrative example of the frustration felt among those participants who served in the role of language broker while transitioning to life in Canada. In her interview, Rose explained that she felt the pressures of her translator role most prominently when she was in a school environment. She described the role of language broker as being very awkward for her, a constant source of embarrassment, and another aspect of her immigrant life which separated her from her peers:

I think just mostly just being a translator and that was a challenge for me because I didn't see how my classmates weren't with their parents on parent-teacher night, but I was because my parents didn't understand my teacher's feedback. Yeah and so [my classmates] they were out playing and I was yep got to go do parent-teacher night. It was just really awkward.

Upon arrival to Canada, Rose quickly observed that her Canadian-born classmates were free to be children during school and did not have the added pressures of having to translate for their parents. Rose felt that the translator role impeded her from fully being a child and was more of an adult job.

Similarly, while reflecting on her past childhood experiences of being a translator for her parents, Eliza also expressed strong feelings about this role arguing that it was not a job a child should have to fulfill:

Not only did I not speak the best English, but I'm like my parents don't know what's going on either. You know you may have noticed that some immigrant families have the child at the forefront of everything. Whereas the parents stand back...they don't know what's going on so they have to send the child to do interpretation or whatever. I had that experience, but I also felt like you know I shouldn't have to be in that role like I'm still a kid. I want to be taken care of instead of doing the opposite.

For both Rose and Eliza, having to serve in the role of language broker not only pre- 
sented immediate challenges during their childhood (i.e. source of embarrassment/ confusion), but the effects of being in this position were felt long into adulthood. More specifically, in each case, serving in this role had long-term impacts on how each participant constructed their identity, their relationship with their parents, and how each related to members of the broader society.

When it comes to childhood language brokering, the findings from our study are consistent with the literature concerning the negative cumulative effects of serving in such a role. As we found, those participants who served in this role reported feelings of depression (Love \& Buriel 2007) and altered identity formation (Kam \& Vanja 2013) more so than those participants who did not provide translation services for their family. Contrary to findings which suggest that language brokering results in heightened feelings of agency and empowerment among immigrant youth (Luykx 2005), the results of our analysis demonstrate that not all children view the role in a positive light. Instead, for some youth, serving in such a role has negative long-term impacts upon how they relate to others in the host society, how they view themselves as immigrants, and how they experience migration.

\section{Importance of Maternal Support with Family Language Policy Planning}

The final area of interest which emerged from our analysis of the family case summaries was the observation that mothers play an integral role in determining whether heritage language learning and maintenance is continued post-migration. Table 3 presents the results of the coded family case summaries in terms of the experiences that the interviewees had by whether they maintained their mother tongue in Canada and the support they received for maintaining their mother tongue from their various family members. The participants in our study who maintained their mother tongue post migration were over four times more likely to express that they received positive support from their mother's while transitioning to Canadian society compared to those who did not maintain their mother tongue in Canada $(46.7 \%$ and $11.1 \%$ of the coded family case summaries respectively). When participants did not maintain their mother tongue in Canada, they often looked to their fathers or extended kin for positive support in the migration process. Our data shows that of the participants who did not maintain their mother tongue in Canada and who had low levels of positive support from their mothers, 33.3\% of their family case summaries were coded for receiving positive support from their fathers and $22.2 \%$ were coded for receiving positive support from their extended kin. Supporting the existing literature on the role of family in learning heritage languages (see Melo-Pfeifer 2014), in our study, extended kin family members were nearly twice as likely to contribute to language maintenance goals than the child's immediate family.

Angela's story, a participant in our study who immigrated from Korea at age 12, is reflective of the struggles faced by immigrant youth when maternal support for family language planning is absent from the migration process. While describing her early days in Canada, Angela reflected on the challenges that she experienced with the support received from her mother in terms of heritage language maintenance. For 
Angela, because her mother provided little support for language maintenance, she felt that she had to hide the desire to preserve her native language and culture from her mother. During her interview, Angela stated that she believed her parents wanted her to integrate and settle in as fast as possible, so they provided very little support for her to maintain contact with her native Korean language and culture. However, feeling isolated from her new peers in Canada due to her lack of knowledge of English and French, Angela longed to have a connection back to Korea and her sense of being Korean. As a result, she sought out covert methods in order to hide this desire from her parents and circumvent the language policy that they adopted as a family:

calling my friends over the...over the phone early in the morning because that would be like nighttime in Korea. I didn't want my parents to know that I was calling my friends in Korea so I put myself in my closet but my Mom happened to be in the bathroom and the closet and the bathroom were connected so just and there's a wall between...only a wall between us. She heard all our conversations and so she was like "Angela what are you doing!"

Table 3. Percentage of the case summaries coded in relation to the interviewee's experiences by family member support

\begin{tabular}{lccc}
\hline \multicolumn{4}{c}{ Percentage distribution } \\
\hline \multicolumn{4}{c}{ MAINTAINED MOTHER TONGUE IN CANADA } \\
\hline $\begin{array}{l}\text { Mother's support } \\
\text { Positive }\end{array}$ & Yes & No & Total \\
Negative & 46.7 & 11.1 & 33.33 \\
& 13.3 & 22.2 & 16.67 \\
Father's support & & & \\
Positive & 20.0 & 33.3 & 25.00 \\
Negative & 6.7 & 11.1 & 8.33 \\
& & & \\
Extended family support & & & \\
Positive & 13.3 & 22.2 & 16.67 \\
Negative & 0.00 & 0.00 & 0.00 \\
& & & \\
\hline Total & $100 \%$ & $100 \%$ & $100 \%$ \\
\hline $\begin{array}{l}\text { (N) "number of coded family case } \\
\text { summaries }\end{array}$ & $\mathbf{1 0}(\mathbf{7 6 . 9 \% )}$ & $\mathbf{3 ( 2 3 . 1 ) \%}$ & $\mathbf{1 3}(\mathbf{1 0 0 \% )}$ \\
\hline
\end{tabular}

Through sharing this memory, Angela described herself as living in-between worlds having to present herself one way to her parents while seeking ways to gain access to her previous pre-migration life.

By contrast, Joanna, a participant in our study who immigrated when she was seven years old from Korea, remembered feeling as though her father feared his children 
were losing their knowledge of Korean. As such, he chose to adapt the family language policy put in place pre-migration so that the family unit only spoke Korean at home while adjusting to life in Canada. To achieve this goal, he went so far as to:

...put a sign on the wall that says Speak Korean! in the house-We [my brother and I] would like mess around with the sign and write different stuff on it. So I guess it was more like our parents were trying to like force the Korean language onto us so we don't like forget it. But, yeah by that time I think we were trying... we were maintaining also like our Korean identity culturally.

As seen in this example, Joanna and her brother rebelled against their father's strict language policy by destroying the sign outlining the family language policy. In her interview, Joanna explained that their response to the family language policy was fueled by the observation that the Korean language held very little value outside their home where all their daily interactions were conducted in English or French.

For participant's whose parents did not form a solid language policy either pre- or post-migration, they often looked to extended kin to support their personal linguistic goals. For example, Eliza, an immigrant from China, felt that she did not have any support at home from her parents to learn either English, French or Mandarin. Growing up in China prior to immigrating to Canada, she saw her aunt develop linguistic skills for her job at a Japanese company and dreamed of being like her one day. Reflecting on her childhood she said:

I had like my aunt for example worked for a Japanese company so she learned a lot of Japanese so I would say like on the languages front there was a strong influence. I would say I had a passion for different cultures or curiosity towards different cultures even at a young age. Um, I don't know if that was ah typical of the Chinese person, but you know I would always look up to my aunt and be like 'Oh she's always going to a Western restaurant and eating with a fork and knife' and that's so cool and I want to be like that you know.

In this case, because Eliza lacked the linguistic support at home to navigate her new life in the host society, the example set forth by her extended kin served as inspiration to learn new languages. By examining Eliza's story, and those of other participants, we find that our results are consistent with the literature on language and migration which suggests that mother's play an integral role in maintaining heritage language learning post migration. Just as these studies have found, our participants were forced to seek out support from their father's or extended kin when their mothers did not provide direct guidance on learning languages or maintaining heritage languages post-migration (Kwon 2017).

\section{DISCUSSION AND CONCLUSION}

Our study examined the ways that parental decisions made throughout an immigrant child's life course regarding language use and learning shape their multilingual identity and attitude towards the use of multiple languages in their everyday adult life. The results of our study suggest that the linguistic decisions parents make in the early 
years of an immigrant youths' life have lasting impacts upon how immigrant youth connect to family members and their native language and culture in adulthood. From working with our participants, we found that when immigrant parents create either a flexible or strict family language policy and adapt it to the evolving needs of immigrant youth, such policies produce more positive experiences in the migration and early settlement processes. Consistent with the literature (see Bammer 1994; Fishman 2001), we conclude that when parents do not create a language policy or provide linguistic support to their children pre- or post-migration, immigrant youth are more likely to experience a negative transition to the host society and find it difficult to connect to their parents in adulthood.

A significant finding shared with the majority of participants in our study was that early childhood experiences as a language broker created residual feelings of resentment by the immigrant youth towards their parents. Our findings support those in the literature, (see Kam \& Vanja 2013) which show that the role of language brokering for immigrant children has several negative effects in terms of role reversals and identity formation processes. For the participants in our study, the childhood pressures of having to translate for their parents in school settings made them feel separated from their Canadian-born peers. From listening to their migration stories, we believe that schools can play an important role in creating a smoother transition for immigrant youth to life in the host society by 1 ) validating the diverse linguistic and cultural repertoires of immigrant youth in Canada through the incorporation of multilingual practices into curricular planning and 2) providing translation services to facilitate communication between home and school. In doing so, immigrant youth will have access to the linguistic tools and support that they need to successfully transition to their post-migration lives.

In our study, gendered differences were found in terms of the adult family members which immigrant children relied upon to seek positive support in maintaining their mother tongue. In accordance with previous findings, we found that when immigrant children lose their mother tongue in the host society, they will increasingly seek support from their fathers and extended kin to support their continued language learning of their heritage languages and connect to their past identity. As such, just as previous studies have found, we concur that mothers play an important role in maintaining and encouraging the use of heritage language learning post-migration (Nesteruk 2010; Tannenbaum 2003). From working with our participants', we too found that when immigrant youth lack linguistic support from their mothers in their transition to the host society, they often feel that they are living in-between worlds as they try to maintain a connection to the past while imagining their post-migration lives. Consequently, to better support their children in the transition to the host society, we argue that it is important for immigrant parents to recognize the unique identity processes and struggles involved in their children's post-migration lives and be prepared to adapt family language policies to meet their evolving linguistic and cultural needs. In doing so, they will provide their children with the necessary linguistic support to transition to life in the host society. 


\section{LIMITATIONS}

Our study had two main limitations the first being that we only had participants who identify as female take part in the research. During the recruitment process, participation in the study was open to all those eligible participants who met the inclusion criteria regardless of their gender identification. In the end, the recruitment process resulted in a higher proportion of females consenting to take part in the research than those who identified as male (13:3). Although three male participants were enrolled in the study, all three were removed as a result of being lost to follow-up. In the end, thirteen participants, all of which identified as female, remained in the study and completed all phases of data collection. The second limitation involved the participants having a similar demographic history in terms of settlement patterns upon arrival to Canada. Of the thirteen participants who completed all stages of data collection, only two settled with their families outside the province of Ontario namely in Québec and British Columbia, Canada respectively. However, due to parental decisions regarding settlement/economic opportunities after immigration to Canada, both participants eventually relocated with their families to Ontario, Canada where they completed the remainder of their schooling.

\section{FUTURE RESEARCH}

Based on our findings, future research in the area of language, migration and youth identity studies might involve combining survey data with in-depth follow-up interviews in order to gather and compare a wider range of experiences stories from multilingual students who grew up in different Canadian or global social contexts. Furthermore, there are few studies within the field which have focused on the impacts for adults with low linguistic abilities living in a bilingual nation. As such, we believe if future research combined multigenerational data from grandparents, parents, and children, the field of language, migration, and youth identity studies research would have a better understanding of the processes involved in the creation of family language policies and the effects these policies have over several generations.

FUNDING: This research received no external funding.

CONFLICT OF INTEREST: The authors declare no conflict of interest.

\section{REFERENCES}

Ayres, Lioness. 2008. “Narrative interview.” Pp. 545-546 in The Sage Encyclopedia of Qualitative Research Methods, edited by L. M. Given. Thousand Oaks, CA: Sage Publications Inc.

Bacallao, Martica L. \& Paul R. Smokowski. 2007. “The Costs of Getting Ahead: Mexican Family System Changes after Immigration.” Family Relations 56(1): 52-66.

Bammer, Angelika. 1994. "Mother tongues and other strangers: Writing 'family' across cultural divides.” Pp. 90-109 in Displacements: Cultural identities in question, ed- 
ited by A. Bammer. Bloomington, IN: Indiana University.

Bodvarsson, Orn Bodvar \& Hendrik Van den Berg. 2013. The economics of immigration: Theory and policy. Dordrecht, Germany: Springer.

Brown, Clara Lee. 2009. "Heritage Language and Ethnic Identity: A Case Study of Korean-American College Students.” International Journal of Multicultural Education 11(1).

Calasanti, Toni M. \& Kathleen F. Slevin. 2006. Age Matters : Realigning Feminist Thinking / Edited by Toni M. Calasanti and Kathleen F. Slevin. New York: Routledge.

Canagarajah, A. Suresh. 2008. "Language Shift and the Family: Questions from the Sri Lankan Tamil Diaspora 1." Journal of Sociolinguistics 12(2): 143-76.

Corsaro, William A. 2018. The Sociology of childhood. Thousand Oaks, CA: Sage Publications.

Cummins, Jim. 2014. “Rethinking Pedagogical Assumptions in Canadian French Immersion

Programs." Journal of Immersion and Content-Based Language Education 2(1): 3-22.

Curdt-Christiansen, Xiao. 2009. "Invisible and Visible Language Planning: Ideological Factors in the Family Language Policy of Chinese Immigrant Families in Quebec.” Language Policy 8(4): 351-75.

Dannefer, Dale. 2003. "Whose life course is it, anyway? Diversity and 'linked lives in global perspective." Pp. 259-268 in Invitation to the life course: Towards new understandings of later life, edited by Settersten \& R. Amityville, NY: Baywood Publishing Company.

Elder, Glen H. 1994. “Time, Human Agency, and Social Change: Perspectives on the Life Course.” Social Psychology Quarterly 57(1): 4-15.

Elder, Glen H. Jr., Monica Johnson, \& Robert Crosnoe. 2003. “The emergence and development of life course theory." Pp. 3-19 in Handbook of the life course, edited by J. T. Mortimer \& M. J. Shanahan. New York, NY: Kluwer Academic/Plenum Publishers.

Espín, Oliva M. 2006. “Gender, sexuality, language, and migration.” Pp. 241-258 in Cultural psychology of immigrants, edited by R. Mahalingam. Mahwah, NJ: Erlbaum.

Ewart, Gestny \& Stan Straw. 2001. "Literacy Instruction in Two French Immersion Classrooms in Western Canada.” Language, Culture and Curriculum 14(2): 187-99.

Feliciano, Cynthia. 2001. "The Benefits of Biculturalism: Exposure to Immigrant Culture and Dropping Out of School Among Asian and Latino Youths.” Social Science Quarterly 82(4): 865-79.

Ferraro, Kenneth F. \& Tetyana Pylypiv Shippee. 2009. "Aging and Cumulative Inequality: How Does Inequality Get Under the Skin?” The Gerontologist 49(3): 333-43.

Fishman,JoshuaA.2001."Fromtheorytopractice(andviceversa):Review,reconsideration and reiteration.” Pp. 451-483 in Can Threatened Languages Be Saved?, edited by J. Fishman. Berlin: Mouton de Gruyter.

Fishman, Joshua A. 1991. Reversing Language Shift: Theoretical and Empirical Foundations ofAssistance to Threatened Languages. Clevedon: Multilingual Matters.

Fishman, Joshua A. 1965. "Bilingualism, Intelligence and Language Learning.” The 
Modern Language Journal (Boulder, Colo.) 49(4): 227-37.

Garbarski, Dana. 2014. "The Interplay Between Child and Maternal Health: Reciprocal Relationships and Cumulative Disadvantage During Childhood and Adolescence." Journal of Health and Social Behavior 55(1): 91-106.

Glick, Jennifer E. 2010. “Connecting Complex Processes: A Decade of Research on Immigrant Families." Journal of Marriage and Family 72(3): 498-515.

Glick, Jennifer E., Laquitta Walker, \& Luciana Luz. 2013. "Linguistic Isolation in the Home and Community: Protection or Risk for Young Children?" Social Science Research 42(1): 140-54.

Hagan, John, Ross Macmillan, \& Blair Wheaton. 1996. "New Kid in Town: Social Capital and the Life Course Effects of Family Migration on Children.” American Sociological Review 61(3): 368-85.

Han, Wen-Jui \& Chien-Chung Huang. 2010. “The Forgotten Treasure: Bilingualism and Asian Children's Emotional and Behavioral health. (RESEARCH AND PRACTICE) (Author abstract)(Report)." The American Journal of Public Health 100(5): 831-38.

Hurtado, Aída \& Luis A. Vega. 2004. "Shift Happens: Spanish and English Transmission Between Parents and Their Children." Journal of Social Issues 60(1): 137-55.

Hutchinson, Elizabeth D. 2007. "A life course perspective." Pp. 1-38 in Dimensions of human behavior: The changing life course, edited by E. D. Hutchinson. Thousand Oaks, CA: Sage.

Jasso, Guillermina. 2003. "Migration, Human Development, and the Life Course.” Pp. 331-364 in Handbook of the life course, edited by J. T. Mortimer \& M. J. Shanahan. Boston, MA: Springer.

Kam, Jennifer A. \& Vanja Lazarevic. 2013. “The Stressful (and Not So Stressful) Nature of Language Brokering: Identifying When Brokering Functions as a Cultural Stressor for Latino Immigrant Children in Early Adolescence." Journal of Youth and Adolescence 43(12): 1994-2011.

Kartch, Falon. 2017. “Narrative interviewing.” Pp. 1073-1075 in The Sage Encyclopedia of Communication Research Methods, edited by M. Allen. Thousand Oaks, CA: Sage Publications Inc.

Kang, Hyun-Sook. 2015. “Korean Families in America: Their Family Language Policies and

Home-Language Maintenance.” Bilingual Research Journal 38(3): 275-91.

Kaveh, Yalda. 2018. "Family Language Policy and Maintenance of Persian: The Stories of Iranian Immigrant Families in the Northeast, USA.” Language Policy 17(4): $443-77$.

Kim Seongeun, Kate Conway-Turner, Bahira Sherif-Trask, \& Tara Woolfolk. 2006. "Reconstructing Mothering Among Korean Immigrant Working Class Women in the United States." Journal of Comparative Family Studies 37(1): 43-58.

King, Kendal A., Lyn Fogle, \& Aubrey Logan-Terry. 2008. "Family language policy.” Language and Linguistics Compass 2(5): 907-9122.

King, Kendall A. \& Lyn Fogle. 2013. "Family language policy and bilingual parenting.” Language teaching 46(2): 172-194. 
Knafl, Kathleen A. \& Lioness Ayres. 1996. "Managing Large Qualitative Data Sets in Family Research.” Journal of Family Nursing 2(4): 350-64.

Kwon, Jungmin. 2017. “Immigrant Mothers' Beliefs and Transnational Strategies for Their Children's Heritage Language Maintenance." Language and Education 31(6): 495-508.

Love, Julia A. \& Raymond Buriel. 2007. “Language Brokering, Autonomy, Parent-Child Bonding, Biculturalism, and Depression: A Study of Mexican American Adolescents From Immigrant Families.” Hispanic Journal of Behavioral Sciences 29(4): 472-91.

Luykx, Aurolyn. 2005. “Children as socializing agents: Family language policy in situations of

language shift.” Pp. 1407-14 in Proceedings of the 4th international symposium on bilingualism, edited by J. Cohen et al. Somerville, MA: Cascadilla Press.

Mady, Callie. 2012. "Official language bilingualism to the exclusion of multilingualism: Immigrant student perspectives on French as a second official language in 'English-dominant' Canada." Language and Intercultural Communication 12(1): 74.

Mayer, Karl Ulrich. 2009. "New Directions in Life Course Research.” Annual Review of Sociology 35: 413-33.

Melo-Pfeifer, Sílvia. 2014. “The Role of the Family in Heritage Language Use and Learning: Impact on Heritage Language Policies." International Journal of Bilingual Education and Bilingualism 18(1): 26-44.

Moen, Phyllis \& Elaine Hernandez. 2009. "Social convoys: studying linked lives in time, context, and motion.” Pp. 258-279 in The Craft of Life Course Research, edited by G. H. Elder \& J. Z. Giele. New York, NY: Guilford Press.

Nesteruk, Olena. 2010. "Heritage Language Maintenance and Loss Among the Children of Eastern European Immigrants in the USA.” Journal of Multilingual and Multicultural Development 31(3): 271-86.

Odrowąż-Coates, Anna. 2019. Socio-educational factors and the soft power of language. Lanham, MD: Lexington Books.

Park, Mi Yung. 2017. "Resisting Linguistic and Ethnic Marginalization: Voices of Southeast Asian Marriage-Migrant Women in Korea.” Language and Intercultural Communication 17(2): 118-34.

Schwartz, Mila. 2010. "Family language policy: Core issues of an emerging field.” $A p$ plied Linguistics Review 1(1): 171-192.

Stevens, Gillian \& Hiromi Ishizawa. 2007. "Variation Among Siblings in the Use of a Non-English Language.” Journal of Family Issues 28(8): 1008-25.

Tannenbaum, Michal. 2003. “The Multifaceted Aspects of Language Maintenance: A New Measure for Its Assessment in Immigrant Families.” International Journal of Bilingual Education and Bilingualism 6(5): 374-93.

Touminen, Anne. 1999. "Who Decided the Home Lagnuage? A Look at Multilingual Families.” International Journal of the Sociology of Language 140: 59-76.

Willson, Andrea, Kim Shuey, \& Glen Elder. 2007. “Cumulative Advantage Processes as Mechanisms of Inequality in Life Course Health.” The American Journal of Sociology 112(6): 1886-1924. 
Yu, Stella M., Jennifer Huang, Renee H. Schwalberg, \& Rebecca M. Nyman. 2006. “Parental English Proficiency and Children's Health Services Access.” The American Journal of Public Health 96(8): 1449-14455.

\section{BIOGRAPHICAL NOTE}

Katherine MacCormac is a $\mathrm{PhD}$ candidate in the Applied Linguistics program at Western University. Katherine's research involves examining the intricate relationship between language, identity, and power in bilingual Canada and its impacts on how multilingual immigrant FSL students negotiate their identities while acquiring proficiency in Canada's official languages. Katherine's research has important implications for the future of Canadian FSL education by highlighting the increased need, from the multilingual immigrant student's perspective, of working towards more inclusive FSL curriculum and pedagogy.

Megan MacCormac is a PhD candidate in the Department of Sociology at the University of Western Ontario. Her research interests include historical sociology, whole family methodology, aging and the life course, and multigenerational mobility. Currently, her doctoral research addresses the lack of three-dimensional models for family research. By expanding the boundaries of whole-family methodology, Megan's work advocates for the use of new research strategies which better reflect the lived experiences and social mobility patterns of whole families and extended kin throughout their life courses.

OPEN ACCESS: This article is distributed under the terms of the Creative Commons Attribution Non-commercial License (CC BY-NC 4.0) which permits any non-commercial use, and reproduction in any medium, provided the original author(s) and source are credited.

ARTICLE HISTORY: Received 2020-10-01 / Accepted 2021-01-23 
